\title{
Rethinking What Is Entrepreneurship Education: A Macro Integrative Perspective
}

\author{
Hongyun $\mathrm{Wu}^{1} \&$ Jibao $\mathrm{Gu}^{2}$ \\ ${ }^{1}$ School of Public Affairs, University of Science and Technology of China, Hefei, China \\ ${ }^{2}$ Graduate School, University of Science and Technology of China, Hefei, Anhui, China \\ Correspondence: Hongyun Wu, School of Public Affairs, University of Science and Technology of China, Hefei \\ 230026, China. Tel: 86-181-5683-5073. E-mail: sherrywu@mail.ustc.edu.cn
}

\author{
Received: December 25, 2016 Accepted: January 30, 2017 Online Published: May 29, 2017 \\ doi:10.5539/ies.v10n6p150 \\ URL: https://doi.org/10.5539/ies.v10n6p150
}

\begin{abstract}
Research on entrepreneurship education (EE) has encountered confusing ontological and methodological issues, such as definitional controversy, gaps between research and practice, and lack of theoretical foundations. These are factors holding back the further development of the research and practice in this field. This paper presents a whole picture of EE by exploring key factors involved in EE programs such as objective, audience, content and method, and assessment with a macro integrative perspective. In this way, it points out the disintegrated micro perspectives employed in prior studies is the source of inadequate understanding of EE, which causes issues and confusions in present EE research. The macro integrative perspective offered by this paper provides an innovative way to tackle these issues and hence is expected to contribute to the further improvement of EE research and practice.
\end{abstract}

Keywords: entrepreneurship education (EE), EE research, macro integrative perspective, entrepreneurial age

\section{Introduction}

The research and practice of EE has achieved a height of prosperity worldwide in the $21^{\text {st }}$ century. However, controversies and issues have been around it since its preliminary stage. To date there is no universally accepted definition of EE (Brockhaus, Hills, Klandt, \& Welsch, 2001; Fayolle, 2010), although there has been consistent effort to define it. EE research seems to be stuck in a definition predicament. Meanwhile EE research has been criticized for lack of theoretical foundation (Fayolle, 2013; Naia, Baptista, Januario, \& Trigo, 2015), too many gaps existing between research and practice, and therefore being fragmented. All the issues centered around EE research point to a sole fact that we don't truly understand what is EE, which demands us to further contemplate the perspectives applied in previous studies on EE's definition. Perceptions on EE through micro lens just lead to context specified findings which have limited contribution to investigating what is EE. Then what is supposed to be the right angle that can help us secure a true cognition of EE? Given issues and limitations of past studies, it is time to revolutionize ways of investigation which we have been taking for granted (Fayolle, 2013). On one hand, the complex and heterogeneous nature of EE determines that it cannot simply be viewed as a compound of entrepreneurship and education instead investigation of its true meaning should be based on a broader perspective. On the other hand, the advent of the entrepreneurial age (Hebert \& Link, 1989; Brockhaus et al., 2001) and the further development of the discipline of EE demand for a macro integrative perspective to integrate EE under the broad economic, political, social and cultural background.

Furthermore, from the stance of education, a review based on a macro integrative perspective of key components involved in EE training and programs leads to a finding that $\mathrm{EE}$ is becoming integrated into various aspects of society in addition to the economic realm. The whole picture of EE presented through the macro integrative perspective will help lead to a more concrete understanding of it, which also provides a theoretical ground for addressing the aforementioned issues in EE research and practice.

\section{Issues Confronted with EE and Its Research}

As a discipline EE is relatively new (Burg \& Romme, 2014; Streeter, Kher, \& Jaquette, 2011; Robinson \& Josien, 2014). Although its prominent growth and positive outcomes are widely acknowledged (Gordon, Hamilton, Jack, 2012; Rauch \& Hulsink, 2015; Ghina, Simatupang, \& Gustomo, 2014; Kuckertz, 2013), EE and its research have 
been surrounded with issues and controversies, for example, debate on whether entrepreneurship can be taught "has continued for many years" (Bliemel, 2014, p. 237), although Drucker declared that it's a discipline which can be learned (Kuratko, 2005), there are still controversies about whether it is teachable.

\subsection{Definitional Controversy along with EE's Remarkable Development}

There are still controversies over an explicit definition of EE (Lyons, Lynn, \& Bhaird, 2015). Alain Fayolle and Heinz Klandt (2006) hold, "As the entrepreneurship concept itself is difficult to define, there is no strong agreement on what entrepreneurship education is and how it could be taught" (Fayolle \& Klandt, 2006, p. 2). There have been lots of arguments upon what is entrepreneur or entrepreneurship since their emergence. Pioneers in this field such as R. Cantillon, J. A. Schumpeter (Kent, 1990) and Peter Drucker (Kuratko, 2005) have made valuable theoretical contribution toward what entrepreneur and entrepreneurship are. However there is still in lack of a generally acknowledged definition of entrepreneurship, which has been criticized as a source of inadequate research both in entrepreneurship and EE (Brockhaus et al., 2001; Fayolle, 2010). These definitional controversies over EE are starting to hold back progress in researches and practices of this field.

However, an undeniable fact is that for decade's entrepreneurship, although "not yet fully recognized, is on its way to being a well-established academic discipline" (Klandt, 2004, p. 293). Nowadays entrepreneurship education has achieved great progress worldwide (Naia et al., 2015; Fayolle, 2013), especially in the USA, whose universities "are generally regarded as the pioneers of academic entrepreneurship education" (Klandt \& Volkmann, 2006, p. 195). According to Kuratko (2005):

Today, entrepreneurship education in U.S. has exploded to more than 2,200 courses at over 1,600 schools; 277 endowed positions; 44 refereed academic journals, mainstream management journals devoting more issues (some special issues) to entrepreneurship; and over 100 established and funded centers.

\subsection{Issues Confronted with EE Research}

Beside controversies researches in this field have been frequently perplexed by other issues which are urgent to be addressed (Fayolle, 2013; Naia et al., 2015).

First, EE research and teaching of entrepreneurship are frequently complained for gaps between theory and practice. Gaps between EE research and practice are drawing increasing attention among researchers (Fayolle, 2013; Naia et al., 2015; Morris, 2014; Steffens, 2014). There are gaps between EE research and real issues entrepreneurs and entrepreneurial activities encounter. Ana Naia et al. (2015) found, "There seems to be a gap in the literature on entrepreneurship education that prevents it from making stronger contributions towards practice" (Naia et al., 2015, p. 111); according to Michael H. Morris, a sizable gap exists between the growing demand for EE and our understanding of how to best approach the teaching and learning of entrepreneurship (Morris, 2014); there are also discrepancies between teaching of entrepreneurship and what entrepreneurs and entrepreneurial activities are truly concerned with. Edelman, Manolova, and Bruch "have highlighted the existence of a gap between what we teach in entrepreneurship and what entrepreneurs do" (as cited in Fayolle, 2013, p. 695).

Second, lack of theoretical foundations is another major concern in current EE research. According to Naia et al. (2015) "Theory-building and its role in the advance of entrepreneurship education has been a longstanding concern in entrepreneurship education research" (Naia et al., 2015, p. 111). Their studies on existing literature in 2000s detect problems in EE research, for instance, "poor theoretical frameworks", "absence of theory-building from case studies", and "lack of a metaparadigm perspective" (Naia et al., 2015, p. 131); "lack of theory" together with "fragmentation", "lack of critical approach", and "lack of legitimacy" are the four major limitations in EE research summarized by Fayolle (2013, p. 697). These researchers all find the absence of a theoretical framework and foundation in EE research fails to provide an overall perspective on the practice of EE. This framework is supposed to be fully based on the characteristics of the discipline of EE instead of a miscellaneous collection of borrowed theories from other fields, for instance, social cognitive theory and theory of planned behavior (Winkler, 2013; Lortie \& Castogiovanni, 2015). Although the application of theories of other fields contributes to some valuable insights and results, these contributions are limited and the whole picture of EE research remains fragmented. Actually fragmented or fragmentation are frequently mentioned in literature as a result of a lack of theoretical frameworks for EE research (Fayolle, 2013; Ghina et al., 2013; Winkler, 2013).

\section{Reflection on the Angle of Perception of EE}

It is evident that the definitional controversy has caught intensive attention from EE researchers and practitioners. It exposes the fact that EE is not truly understood and it proves to be a primary cause for other controversies and issues such as research gaps, fragmentation, absence of theoretical foundation and even skepticism towards 
legitimacy of EE (Fayolle, 2013). Then what is on the way of a true understanding of EE? In 2013, Alain Fayolle began his questioning upon the rationality of prior angles employed in EE research, and what he suggested is thought-provoking:

In view of these issues and challenges, I would suggest that, for the future of EE...we need to reflect upon our practices and take a more critical stance, breaking away from the far too common 'taken for granted position'(Fayolle, 2013, p. 693).

\subsection{The New Era's Call for a Revolution in Research Stances}

To better comprehend the importance of a right angle of perception of a real understanding of EE, we'd better first briefly review changes in the ways of interpretation of entrepreneurship. At the very beginning entrepreneurship was viewed as a concept related to ventures and economic growth by economists such as Schumpeter and Gunderson (Kent, 1990). Now the world is different from which those renowned economists lived in, and approaches to explaining entrepreneurship have therefore shifted from the traditional economic stance to a modern broader one. Some researchers hold that entrepreneurship not only refers to starting up businesses but also it defines a spirit of proactively taking risks and seeking opportunities (Kuratko, 2005); some think it can be viewed as "a matter of culture (institutional point of view) or a state of mind" (individual point of view), it is also "a matter of behaviours" or "specific situations" (Fayolle \& Klandt, 2006, p. 2). Although the persistent efforts by entrepreneurship researchers have not yet resulted in reaching a consensus on an universal definition of it (Brockhaus et al., 2001), it is noteworthy that ways of perception of this notion has transcended beyond socio-economic stance toward a more holistic direction, which is leading a once fragmented entrepreneurship research ahead as a legitimate area of academic inquiry to a mature and systematic direction (Acs \& Audretsch, 2010; Busenitz, 2014).

Now EE research is confronted with the same bewilderment of definition problem as that of entrepreneurship. EE has been defined by many scholars, yet disagreement still remains about its explicit meaning (Lyons \& Lynn, 2015; Fayolle \& Klandt, 2006). Although the uncertainty of such concepts as entrepreneur and entrepreneurship makes it an even complicated task to get an explicit definition of EE, it prospers worldwide and now is arguably a legitimate and critical discipline. According to Robert Tonstadt "a new era of entrepreneurial education" (as cited in Kent, 1990, p.71) is arriving. However, the inadequate understanding of EE and fragmented EE research without a theoretical foundation are undermining EE's contribution to the entrepreneurial era. Studies on EE theoretical frameworks or practical methods are often context-specific (Naia et al., 2015), and researches of theory building and testing based on single paradigms are not conducive to more complete cognition (Naia et al., 2015).

\subsection{The Need for a Shift from Micro to Macro Perspective}

Given the existing problems confronted with EE research, it is imperative that we should meditate again upon what we call the discipline of EE, but undoubtedly with a new critical lens. There are too many micro level data, content-specific cases, and individual level studies that regard EE as an academic discipline based on the combination of knowledge from entrepreneurship and education (Naia et al., 2015; Fayolle, 2013). Static and disintegrative lens focusing on individual cases and groups of participants isolate EE research from the heterogeneous background in which EE is embedded, which is destined to result in more gaps, disconnections and fragmentations. The widely applied micro angles, such as socio-economic perspective, prove to be both blesses and curses for the EE research, whose context specific findings do bring some practical references to the development of EE, but they have resulted in great limitations to the further development of EE, too, for example, Martin Lackeus (2015) states that "the emphasis on economic effects has so far hampered a widespread adoption of entrepreneurial education in the remaining parts of the educational system" (Lackeus, 2015, p. 18). It is evident that EE researches based on a micro perspective can't meet the need for "a unifying theoretical framework that can be universally applied" (Winkler, 2013, p.71-73) in today's entrepreneurial age (Brockhaus et al, 2001).

It is necessary for the angle of perception to change into a holistic and integrative direction to better define EE, to build a cohesive theoretical framework, and to bridge disconnections and gaps in EE research and practice (Fayolle, 2013). A macro integrative perspective is the key to define EE, to address issues of it, and to steer it to the entrepreneurial era.

\section{The Internal Demand of EE-A Macro Integrative Perspective}

The pursuit of knowledge of nature, man, and society has been an essential task for people including philosophers for a long time. Ideas and theories of the great minds in the West from Socrates and Plato to Hegel 
and Feuerbach have inspired us to apply resourceful perspectives to observe the ever changing world. In the East works of ancient philosophers, I Ching and Tao Te Ching, for example, advocate a harmonious integrity among people, nature and society. Although philosophical perspectives on nature and human society diverse whether it is in the east or west, it is clear that the integrity among nature, man and society has gained wide acknowledgement among people in the past and present. Nowadays modern high technology, transit communications and transportations make the world become a global village, and different aspects of the world are becoming increasingly interrelated. To better understand and adapt to the ever changing modern world, it is necessary for people to view the world with a broad dynamic and an integrative horizon.

\subsection{A Macro Integrative Perspective: The Demand of Education in the Entrepreneurial Age}

Education as an important aspect of human society and culture has undergone substantial changes as well. Take history of education in the US for example, from schools in families to those in communities, from those exclusively for white boys to those including girls and blacks, from elementary to university, American education system has witnessed a change from isolation to openness, from basic literacy training to holistic education. The development process of education reveals its important role in serving as a bridge between knowledge and human society, a principle inherent in education that still persists even under the increasingly sophisticated circumstances of modern society. With the advent of knowledge economy and globalization, the role of education serving as a driver to generate knowledge into economic growth becomes increasingly evident and crucial. Meanwhile Economic factors play more and more important role in changing educational objectives, curricula, and pedagogies. Under this circumstance the link between education and economy has been strengthened unprecedentedly. In the entrepreneurial age today (Brockhaus et al., 2001), the remarkable growth of EE has exhibited a tremendous demand for education to promote entrepreneurship. However, the inherent tie between education and society as well as culture should by no means be limited to educational effects on economic growth which has been considered of pivotal importance in EE. The encompassing nature of EE determines it should be viewed as a holistic and integrative process (Ray, 1990) in which the educational process of EE interweaves with factors in economy, politics, society and culture. The study of EE's definition and lens for EE research should be based on a philosophy which overviews EE as an integrated part of society instead of a discipline concerning just business and economy. A macro integrative perspective is consistent with the internal demand of $\mathrm{EE}$ as a discipline of education.

\section{A Macro Integrative Perspective on What is EE}

The discussion of components of EE programs usually covers aspects such as: objective or goal (Fayolle, 2013; Kuckertz, 2013; Mwasalwiba, 2010); audience (Fayolle, 2013; Kuckertz, 2013); content and method (Fayolle, 2013; Kuckertz, 2013; Kozlinska, 2011; Maritz \& Brown, 2013); assessment (Fayolle, 2013; Maritz \& Brown, 2013; Mwasalwiba, 2010). Although the criteria for identification of these factors vary with specific programs under the micro perspective, investigations of the components on the basis of a macro integrative perspective will present us a more comprehensive picture of EE, which is beyond the contextual and individual case of EE program, and hence is conducive to the construction of a real understanding of EE. In the following paragraphs a panoramic view of EE will be presented based on a macro integrative perspective on these key factors $\mathrm{EE}$ is concerned with.

\subsection{EE's Objective or Goal}

The objective or goal of EE under a macro lens includes both narrow and wide views (Nasr \& Boujelbene, 2014). There still remains confusion about what EE's objective should be (Maritz \& Brown, 2013). At the very early stage of entrepreneurship it seemed a word solely regarding to economic growth (Carland, Hoy, \& Boulton et al., 1984; Kent, 1990). Similarly, economic motivation for new venture creation has been at the center of traditional EE objectives. Although it is acknowledged not the same as business management education, it was primarily as "courses in small business management" (Kent, p.9) at the very beginning. At the didactical level, EE is expected to enhance participants' temperament and competency for business creation related activities, for example self-confidence, capability of opportunity detection and venture operation, as well as interpersonal communication skills.

With the goal of teaching and learning skills of initiating new businesses or managing existing businesses remains at the center, modern EE objectives, however, have evolved into a broader sense. Take EE at the university level for example, to cultivate an entrepreneurial mindset or spirit in university students is a crucial goal that EE should meet in a globalized knowledge world (Thorp \& Goldstein, 2010; Zhao, 2012). The mindset or spirit is not only concerned with venture starting and revenues but also an engagement with the benefit of society, which can be witnessed through social entrepreneurial activities on some university campuses, for 
instance, in Stanford, a top entrepreneurial university in the US. Social entrepreneurship is an organic part of innovation and entrepreneurship in Stanford. There's a magazine named Stanford Social Innovation Review, aiming to bring changes to the world through integrating social entrepreneurial spirit into academic theory and practice (Stanford University, n.d.). Besides there are many programs for social entrepreneurship (Stanford Graduate School of Business, n.d.), and there social innovation and social venture are discussed as naturally as technological innovation and business venture. In addition, it is widely acknowledged that entrepreneurs' values greatly affect the businesses they own. Entrepreneurs identifying with the value of serving the society will bring a spirit of doing good deed for society into their business ethics, which is believed to be closely associated with their business economic profits (Besser, 2012; Vranceanu, 2014). Therefore the objective of EE under a macro perspective should be directed by a principle to integrate enhancing entrepreneurial competence with fostering entrepreneurs' values of doing good deed for society. This objective is not only applicable to the practice of specific programs and cases and effective to their short-term outcomes but it contributes to the long-term impact of EE programs and trainings (Nasr \& Boujelbene, 2014).

\subsection{EE's Audience}

At whom EE is supposed to target? Although entrepreneurship courses and programs were predominantly for business students in the early years and have achieved a height of maturity in American business schools, specifically designed EE courses and programs for non-business students have also grown tremendously (Katz, 2003; Kuratko, 2005). America has entered "a new era of entrepreneurial education" (Ronstadt as cited in Kent, 1990, p. 71). Early in 1985, in an address to the nation President Reagan applied "Age of the Entrepreneur" to envisage the US future (Hebert \& Link, 1989, p. 40). James O. Fiet (2001) also claimed that "The United States is entering an important new era of entrepreneurship" (as cited in Brockhaus et al., 2001, p. 78). The passion for entrepreneurial activity has been at a height. Donald F. Kuratko's studies found that "approximately one new firm with employees is established every year for every 300 adults in the U.S. ... Substantially, more-1 in 12 - are involved in trying to launch a new firm" (Kuratko, 2005, p. 578). Under this circumstance, EE at the collegiate level has achieved tremendous development. Gary Rabbior (1990) stated that to judge who are to be likely candidates is pointless, and we should "assign the potential for entrepreneurship to every young person" (as cited in Kent, 1990, p. 54). Nowadays the expansion of EE has swept from higher education to secondary and even the entire K-12 school system (Kent, 1990; Johansen \& Schanke, 2013). However, it seems that EE not only involves every student in the educational system from K-12 through collegiate level but it appeals to workers, employees, and even entrepreneurs themselves. Actually in America programs offered by universities "serve many different audiences"(Kent, 1990, p.9), including undergraduate and graduate students in colleges and universities, as well as existing and prospective entrepreneurs who are not students on regular enrollment; teachers at all levels in the educational system are also offered training by many universities to help them teach entrepreneurship; there are even programs designed by universities and colleges for those whose work is supposed to closely related to entrepreneurs, for instance, "bankers, lawyers, consultants, government officials and Certified Public Accountants (Kent, 1990, p.9)". With the world entering an entrepreneurial age it seems that everyone can be the potential audience of EE regardless of the sex, career, nationality and ethnicity.

\subsection{EE's Content and Method}

Content and method of EE are usually referred to as questions of what to teach and how to teach (Mwasalwiba, 2010; Solomon, 2007; Fayolle, 2013). In some research the instructor is also considered a factor in the observation of this part, which is usually referred to as the question of who to teach (Fayolle, 2013; Kuckertz, 2013).

As the forefront of EE there are in the US various courses and programs offered to teach entrepreneurship. In some degree entrepreneurial and managerial courses, for example, microfinance, economic development, and small business management overlap, however, entrepreneurship courses have their peculiar characteristics. They are often offered in a multi-disciplinary setting, for example indigenous business organization courses in sociology and high-tech entrepreneurship in engineering schools (Katz, 2003). American entrepreneurial universities offer various interdisciplinary courses for EE participants. The Academy for Innovation \& Entrepreneurship of University of Maryland for example provides 141 I\&E courses designed and taught by a multidisciplinary team of faculty, dealing with tough problems in various fields and disciplines including arts and humanities, as well as behavioral and social sciences(University of Maryland, n.d.). Besides, the importance of liberal arts education in EE has gained increasing approval in theory and practice (Ray, 1990). Stanford values a culture to foster a broad liberal arts foundation for its undergraduate education (Stanford University, n.d.), which has an inseparable relation to its outstanding status as the nation's top entrepreneurial university. More important than academic and theoretical training, the content of EE training and programs is becoming 
increasingly competence oriented, which aims at enhancing multi-dimensional competencies and soft skills in various fields, such as venture financing, corporate entrepreneurship, and entrepreneurial strategies (Kuratko, 2005), as well as specific skills in negotiation, leadership (Kuckertz, 2013; Ulvenblad, Berggren, \& Winborg, 2013) and "deal-making" skill (Ronstadt as cited in Kent, 1990, p.79). Beside entrepreneurial competences, EE programs start to be engaged in community outreach activities as EE is considered a component of social support system (Mwasalwiba, 2010). Furthermore, as ethics in business has gained rapidly increasing attention (Kent, 1990; Kuratko, 2005; Tesfayohannes \& Driscoll, 2010), it is also supposed to be an integrated part in the EE curriculum.

EE pedagogy is changing (Kuratko, 2005; Hägg, 2016). Teaching paradigm has shifted from focus on instructors' how to teach to participants' what to do (Fayolle \& Klandt, 2006; Brockhaus et al., 2001; Hägg, 2016). Traditional EE teaching method, mainly in the form of lecture delivery has been replaced by more "dynamic pedagogy" in "blended, online and flipped approaches" (Maritz, Koch \& Schmidt, 2016, p.21). The traditional passive teaching which focuses on knowledge imparting has been substituted for active competence-based experiential learning (Lans \& Hulsink, 2008; Kozlinska, 2011; Kuckertz, 2013; Rahman \& Day, 2015) and action learning(Maritz \& Brown, 2013). Examples of experiential learning tools are: business plans, case studies, action researches, behavioral simulations (Kuratko, 2005; Kozlinska, 2011), and internship (Kourisky as cited in Kent, 1990) to name a few. Beside the pedagogical change, the scenario for EE also takes on a new look. The EE practice has extended from classroom and on-campus environment to real business world settings (Kuratko, 2005; Maritz \& Brown, 2013).

With the transformation of EE teaching paradigm, the focus has shifted from instructors to learners. There is rarely any systematic research on the problem of who to teach EE, and whether EE educators should possess "prior entrepreneurial expertise" (Fayolle, 2013, p. 695). However, a shortage of qualified EE staff has become a worldwide concern, which is adversely restricting EE's development (Kuckertz, 2013; Katz, 2003). At present, faculties in universities and colleges take major responsibilities to teach entrepreneurship, in some cases, in forms of cross discipline faculty teams, for example the case of UMD. Some researchers find it's effective to involve entrepreneurs as role models into EE training and programs (Rahman \& Day, 2015). To get entrepreneurs involved in presentations and interviews on campus or providing students' internship opportunities off campus has been perceived by universities and colleges as an effective way to enhance entrepreneurship teaching and learning. In this sense, qualified candidates of EE instructors are not limited to faculties in universities and colleges, instead they should also include entrepreneurs or anyone who can provide EE participants knowledge and skill related to entrepreneurship.

\subsection{EE's Assessment}

The assessment of EE is closely related to program objectives, contents, and pedagogies (Maritz \& Brown, 2013), and is a difficult and complicated process (Fayolle \& Degeorge, 2006). There is much disagreement on the assessment of EE programs and courses (Lyons et al., 2015). The particular criteria and measures for outcomes and impacts of EE programs vary with the different entrepreneurship training contents, as well as different objectives set by different stakeholders (Fayolle \& Klandt, 2006). The outcomes and effects are usually multi-dimensional and some of them, for example, venture creation, "cannot possibly be measured during or immediately after training (Fayolle \& Degeorge, cited in Fayolle \& Klandt, 2006, p. 75)". Although the micro perspectives, for example, the trait theory, planned behavior theory and social cognitive lenses are commonly applied in measuring EE outcomes at the individual level (Lyons et al., 2015), there lacks a systematic perspective for the assessment of EE to construct more cohesive analysis at a macro level (Lyons et al., 2015). The EE training programs that are associated with practices and behaviors at the micro level do have macro level implications (O'Connor, 2013) and contain objectives beyond economic factors (Maritz \& Brown, 2013). Under this circumstance, the assessment of EE programs whether at the institutional or individual level should be directed by a broad and integrative stance.

It is evident that discussion of these components involved in EE programs is widely spread, however, the study of "the dynamic relationships and integration of the components" of EE programs has been considered as "a black box" (Maritz and Brown, 2013, p.235), an unknown and key part in discovering the secret of EE. Under this macro integrative perspective, these components are all interrelated and are integrated parts of EE within the broad economic, political, social, cultural and global circumstances of the present entrepreneurial age.

\section{Conclusion}

There have been lots of studies into what is EE and how to promote EE's practice (Kent, 1990; Fayolle, 2010; Fayolle \& Klandt, 2006; Brockhaus et al., 2001). However, EE's development has been confronted with 
definitional controversies, research gaps and lack of theoretical foundations, which have sustained for quite a long time and have begun to hold back its further progress. The widely applied micro angles, such as socio-economic perspective, prove to be both blesses and curses for the EE research, whose context specific findings do bring some practical references to the development of EE but great limitations have been exposed too. The entrepreneurial age calls for a methodological revolution in both EE research and practice.

Through an examination based on a macro integrative perspective on key factors involved in EE this study results in a bold finding that $\mathrm{EE}$ is becoming integrated into various aspects of society in addition to the economic realm. The panoramic view of what is EE presented through this perspective is challenging our traditional cognition about discipline with a set of new phenomena: it aims to teach knowledge and skills not only necessary for business but for life, as well as the mindset to serve society; it involves nearly people of all ages in all nations and of all walks of life as audiences, instructors, entrepreneurs and policy makers; besides business subjects it integrates courses of science, arts and ethics into entrepreneurial curricula, and it brings a revolution in pedagogy by linking teaching and learning with working and living; it also brings a revolution to the traditional understanding of the role of universities as institutions for intellectual heritage. The ivory tower now is embracing teaching and learning of entrepreneurship (Fayolle \& Klandt, 2006). Under this macro integrative perspective $\mathrm{EE}$ is viewed as a discipline integrated with the process of economic activities, government policy making, social welfare improvement, and cultural enhancement, encompassing wide participation by various groups of people and institutions, aiming to empower participants entrepreneurial ability and mindset for multicultural and globalized setting. The whole picture of EE presented through the macro integrative perspective lead to a more concrete and holistic understanding of $\mathrm{EE}$, which also provides an ontological ground to the addressing of aforementioned issues to bridge gaps in EE research and practice, and to build theoretical foundations for the discipline. Only when EE research makes breakthrough in the understanding of EE itself can significant improvement be made in EE practice.

\section{References}

Bliemel, M. J. (2014). Getting Entrepreneurship Education Out of the Classroom and into Students' Heads, Entrepreneurship Research Journal, 4(2), 237-260.

Brockhaus, R. H., Hills, G. E., Klandt, H., \& Welsch, H. P. (Eds.). (2001). Entrepreneurship Education: A Global View. Burlington, VT, USA: Ashgate Publishing Company.

Burg, E. V., \& Romme, G. (2014). Creating the Future Together: Toward a Framework for Research Synthesis in Entrepreneurship. Entrepreneurship Theory and Practice, March, 1-40.

Busenitz, L. W., Plummer, L. A., Klotz, A. C., Shahzad, A., \& Rhoads, K. (2014). Entrepreneurship Research (1985-2009) and the Emergence of Opportunities. Entrepreneurship Theory and Practice, 38(5), 981-1000. https://doi.org/10.1111/etap.12120

Carland, J. W., Hoy, F., Boulton, W. R. et al. (1984). Differentiating Entrepreneurs from Small Business Owners: A conceptualization. Academy of Management Review, 9, 354-359.

Draycott, M. C., Rae, D., \& Vause, K. (2011). The Assessment of Enterprise Education in the Secondary Education Sector: A New Approach? Education + Training, 53(8-9), 673-691. https://doi.org/10.1108/00400911111185017

Fayolle, A. (2013). Personal Views on the Future of Entrepreneurship Education. Entrepreneurship \& Regional Development, 25(7-8), 692-701. https://doi.org/10.1080/08985626.2013.821318

Fayolle, A. (Ed.). (2010). Handbook of Research in Entrepreneurship Education Vol. 3: International Perspectives. Cheltenham, UK: Edward Elgar Publishing Limited.

Fayolle, A., \& Degeorge, J. M. (2006). Attitudes, Intentions and Behavior: New Approaches to Evaluating Entrepreneurship Education. In A. Fayolle \& H. Klandt (Eds.), International Entrepreneurship Education: Issues and newness (pp. 74-92). Cheltenham, UK: Edward Elgar Publishing Limited.

Fayolle, A., \& Klandt, H. (Eds.). (2006). International Entrepreneurship Education: Issues and newness, Cheltenham. UK: Edward Elgar Publishing Limited.

Fiet, J. O. (2001). Education for Entrepreneurial Competency: A Theory-based Activity Approach (pp. 78-93). In R. H. Brockhaus, G. E. Hills, H. Klandt, \& H. P. Welsch (Eds.), Entrepreneurship Education: A global view. Aldershot: Ashgate.

Ghina, A., Simatupang, T. M., \& Gustomo, A. (2014). A Systematic Framework for Entrepreneurship Education within a University Context. International Education Studies, 7(12), 1-19. 
https://doi.org/10.5539/ies.v7n12p1

Gordon, I., Hamilton, E., \& Jack, S. (2012). A Study of A University-led Entrepreneurship Education Programme for Small Business Owner/Managers. Entrepreneurship \& Regional Development, 24(9-10), 767-805. https://doi.org/10.1080/08985626.2011.566377

Hägg, G. (2016). Connecting the Dots: A discussion on Key Concepts in Contemporary Entrepreneurship Education. Education + Training, 58(7/8), 700-714. https://doi.org/10.1108/ET-12-2015-0115

Hebert, R. F., \& Link A. N. (1989). In Search of the Meaning of Entrepreneurship. Small Business Economics, 1(1), 39-49. https://doi.org/10.1007/BF00389915

Johansen, V., \& Schanke, T. (2013). Entrepreneurship Education in Secondary Education and Training, Scandinavian Journal of Educational Research, 57(4), 357-368. https://doi.org/10.1080/00313831.2012.656280

Katz, J. A. (2003). The Chronology and Intellectual Trajectory of American Entrepreneurship Education 1876-1999. Journal of Business Venturing, 18(2), 283-300. https://doi.org/10.1016/S0883-9026(02)00098-8

Kent, C. A. (Ed.). (1990). Entrepreneurship Education: Current Developments, Future Directions. Westport, Connecticut: Quorum Books.

Klandt, H. (2004). Entrepreneurship Education and Research in German-Speaking Europe. Academy of Management Learning and Education, 3 (3), 293-301. https://doi.org/10.5465/AMLE.2004.14242226

Klandt, H., \& Volkmann, C. (2006). Development and Prospects of Academic Entrepreneurship Education in Germany. Higher Education in Europe, 31(2), 195-208. https://doi.org/10.1080/03797720600940880

Kourilsky, M. (1990). Entrepreneurial Thinking and Behavior: What Role the Classroom? In C. A. Kent (Ed.), Entrepreneurship Education: Current Developments, Future Directions (pp. 137-152). Westport, Connecticut: Quorum Books.

Kozlinska, I. (2011). Contemporary Approaches to Entrepreneurship Education. Journal of Business Management, 4, 205-220.

Kuckertz A. (2013). Entrepreneurship Education: Status Quo and Prospective Developments. Journal of Entrepreneurship Education, 16(1), 59-71.

Kuratko, D. (2005). The Emergence of Entrepreneurship Education: Development, Trends, and Challenges, Entrepreneurship Theory and Practice, 29(5), 577-597. https://doi.org/10.1111/j.1540-6520.2005.00099.x

Lackeus, M. (2015). Entrepreneurship in Education-What, Why, When, How. Entrepreneurship360 Background Paper, OECD, France.

Lans, T., \& Hulsink, W. (2008). Entrepreneurship Education and Training in a Small Business Context: Insights from the Competence-based Approach. Journal of Enterprising Culture, 16(4), 363-383. https://doi.org/10.1142/S0218495808000193

Lortie, J., \& Castogiovanni, G. (2015). The theory of planned behavior in entrepreneurship research: what we know and future directions. International Entrepreneurship and Management Journal, 11(4), 935-957. https://doi.org/10.1007/s11365-015-0358-3

Lyons, R., Lynn, T., \& Bhaird, M. C. (2015). Individual Level Assessment in Entrepreneurship Education: An Investigation of Theories and Techniques. Journal of Entrepreneurship Education, 18(1), 136-156.

Maritz, A., \& Brown, C. R. (2013). Illuminating the Black Box of Entrepreneurship Education Programs, Education+Training, 55(3), 234-252. https://doi.org/10.1108/00400911311309305

Maritz, A., Koch, A., \& Schmidt, M. (2016). The Role of Entrepreneurship Education Programs in National Systems of Entrepreneurship and Entrepreneurship Ecosystems. The International Journal of Organizational Innovation, 8(4), 7-26.

Murphy, M. M. (1990). Interns and Mentorships in Entrepreneurship Education Programs. In C. A. Kent (Ed.). Entrepreneurship Education: Current Developments, Future Directions (pp. 243-259). Westport, Connecticut: Quorum Books.

Mwasalwiba, E. S. (2010). Entrepreneurship education: A review of Its Objectives, Teaching Methods, and Impact Indicators. Education + Training, 52 (1), 20-47. https://doi.org/10.1108/00400911011017663

Naia, A., Baptista, R., Januário, C., \& Trigo, V. (2015). Entrepreneurship Education Literature in the 2000s. 
Journal of Entrepreneurship Education, 18(1), 111-135.

Nasr, K. B., \& Boujelbene, Y. (2014). Assessing the Impact of Entrepreneurship Education. Procedia - Social and Behavioral Sciences, 109, 712-715. https://doi.org/10.1016/j.sbspro.2013.12.534

O’Connor, A. (2013). A Conceptual Framework for Entrepreneurship Education Policy: Meeting Government and Economic Purposes. Journal of Business Venturing, 28(4), 546-563. https://doi.org/10.1016/j.jbusvent.2012.07.003

Rabbior, G. (1990). Elements of a Successful Entrepreneurship/Economics/Education Program. In Kent C. A. (Ed.), Entrepreneurship Education: Current Developments, Future Directions (53-65). Westport, Connecticut: Quorum Books.

Rahman, H., \& Day, J. (2015). Involving the Entrepreneurial Role Model: A Possible Development for Entrepreneurship Education. Journal of Entrepreneurship Education, 18(1), 86-95.

Rauch, A., \& Hulsink, W. (2015). Putting Entrepreneurship Education Where the Intention to Act Lies: An Investigation Into the Impact of Entrepreneurship Education on Entrepreneurial Behavior. Academy of Management Learning \& Education, 14(2), 187-204. https://doi.org/10.5465/amle.2012.0293

Ray, D. (1990). Liberal Arts for Entrepreneurs, Entrepreneurship Theory and Practice, winter, 79-90.

Robinson, P., \& Josien, L. (2014). Entrepreneurial education: Using "the challenge" in theory and practice. Journal of Entrepreneurship Education, 17(2), 172-185.

Solomon, G. (2007). An Examination of Entrepreneurship Education in the United States, Journal of Small Business and Enterprise Development, 14(2), 168-182. https://doi.org/10.1108/14626000710746637

Stanford Graduate School of Business. (n.d.). Executive Program in Social Entrepreneurship. Retrieved October 21, 2016, from https://www.gsb.stanford.edu/programs/executive-program-social-entrepreneurship

Stanford University. (n.d.). Academics. Retrieved October 18, 2016, from https://www.stanford.edu/academics/

Stanford University. (n.d.). Stanford Social Innovation Review. Retrieved October 20, 2016, from https://ssir.org/

Steffens, P. R., Weeks, C. S., Davidsson, P., \& Isaak, L. (2014). Shouting From the Ivory Tower: A Marketing Approach to Improve Communication of Academic Research to Entrepreneurs. Entrepreneurship Theory and Practice, 38(2), 399-426. https://doi.org/10.1111/etap.12079

Streeter, D. H., Kher, R., \& Jaquette, J. P. (2011). University-wide Trends in Entrepreneurship Education and the Rankings: A dilemma, Journal of Entrepreneurship Education, 14, 75-92.

Tesfayohannes, M., \& Driscoll, C. (2010). Integrating Ethics into Entrepreneurship Education: An Exploratory Textbook Analysis. Journal of Entrepreneurship Education, 13, 85-106.

Ulvenblad, P., Berggren, E., \& Winborg J. (2013). The Role of Entrepreneurship Education and Start-up Experience for Handling Communication and Liability of Newness. International Journal of Entrepreneurial Behavior \& Research, 19(2), 187-209. https://doi.org/10.1108/13552551311310374

University of Maryland. (n.d.). Fearless Ideas Courses. Retrieved October 12, 2016, from http://innovation.umd.edu/learn/

Winkler, C. (2013). Toward a Dynamic Understanding of Entrepreneurship Education Research across the Campus - Social Cognition and Action Research. Entrepreneurship Research Journal, 4(1), 69-93. https://doi.org/10.1515/erj-2013-0039

\section{Copyrights}

Copyright for this article is retained by the author(s), with first publication rights granted to the journal.

This is an open-access article distributed under the terms and conditions of the Creative Commons Attribution license (http://creativecommons.org/licenses/by/4.0/). 